\title{
Effectiveness of energy-restricted diets with different protein:carbohydrate ratios: the relationship to insulin sensitivity
}

\author{
María D Ballesteros-Pomar*, Alicia R Calleja-Fernández, Alfonso Vidal-Casariego, \\ Ana M Urioste-Fondo and Isidoro Cano-Rodríguez \\ Endocrinology and Nutrition Department, Complejo Asistencial de León, Altos de Nava s/n, \\ E-24008 León, Spain
}

Submitted 29 January 2009: Accepted 25 September 2009: First published online 5 November 2009

\begin{abstract}
Objective: Insulin sensitivity could determine the effectiveness of weight-loss diets with different protein:carbohydrate ratios. Our aim was to evaluate whether or not energy-restricted diets with different protein:carbohydrate ratios in obese individuals with (IR) or without (IS) insulin resistance could lead to differences in weight loss or insulin sensitivity.

Design: Prospective, randomized, clinical intervention study. Thirty-six obese patients, allocated to the IR or IS group after a $75 \mathrm{~g}$ oral glucose tolerance test and calculation of the homeostasis model assessment of insulin resistance (HOMA) index, were assigned to follow an energy-restricted diet with either $40 \%$ carbohydrate $/ 30 \%$ protein $/ 30 \%$ fat (diet A) or 55\% carbohydrate/15\% protein $/ 30 \%$ fat (diet B) and followed up to 16 weeks.

Results: Twenty-one IR and fifteen IS patients were randomized to diet A or B. After 16 weeks, there was no difference in weight loss between diets A and B in each group. Glucose and insulin levels and HOMA were significantly reduced at 16 weeks, but no differences related to the type of diet were detected either in the IR or the IS group.

Conclusions: Varying the macronutrient composition of a hypoenergetic diet, regarding the percentage protein:carbohydrate ratio, did not produce different weight loss or result in an improvement in insulin sensitivity in people with or without insulin resistance.
\end{abstract}

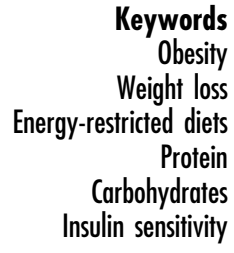

Obesity

diets

Protein

Carbohydrates
The prevalence of obesity is increasing rapidly ${ }^{(1)}$. The first clinical approach for the treatment is dietary-induced weight loss, but the most effective dietary changes are now under debate. Some recent reports have popularized the previously withdrawn endorsement of certain dietary approaches, especially those with low carbohydrate intake ${ }^{(2-6)}$. Those favouring low-carbohydrate diets postulate that insulin resistance and high insulin levels promote obesity and that a drastic carbohydrate intake decrease could reduce insulin levels and result in greater weight loss $^{(7)}$. A recent meta-analysis, however, has shown that low-carbohydrate diets could result in a greater weight loss in the first 6 months but not in the long term ${ }^{(8)}$. Indeed, the main variable predicting the amount of weight loss was dietary compliance, regardless of the type of $\operatorname{diet}^{(9)}$. Moreover, a randomized trial comparing four low-energy diets with various compositions of fat, protein and carbohydrate over a 2 -year period found similar weight loss, satiety, hunger and compliance, regardless of which macronutrients they emphasized ${ }^{(10)}$. Cornier et $a l^{(11)}$, however, recently reported that the insulin sensitivity state could influence the effectiveness of hypoenergetic diets with different carbohydrate content and carbohydrate:protein ratios in obese individuals. Thus, we tried to evaluate two hypoenergetic diets with different protein:carbohydrate ratios in obese individuals either with (IR) or without (IS) insulin resistance regarding weight loss and changes in insulin sensitivity.

\section{Methods}

Thirty-six obese or overweight patients (BMI $28-35 \mathrm{~kg} / \mathrm{m}^{2}$, aged 18-70 years) were enrolled in the Endocrinology Clinic in the Complejo Asistencial de León, Spain. Although forty patients were initially screened, only thirty-six volunteered and completed the 16-week intervention. Exclusion criteria were weight-loss treatment in the previous 6 months, psychiatric illness, diabetes (fasting plasma glucose $>126 \mathrm{mg} / \mathrm{dl}$ or $>200 \mathrm{mg} / \mathrm{dl}$ at $120 \mathrm{~min}$ after a $75 \mathrm{~g}$ oral glucose tolerance test (OGTT)), eating disorder, previous bariatric surgery or pregnancy. Patients 
were placed in either the IR or the IS group after the $75 \mathrm{~g}$ OGTT and calculation of the homeostasis model assessment of insulin resistance (HOMA) index. The HOMA index was calculated as the product of the fasting plasma insulin level $(\mathrm{mU} / \mathrm{ml})$ and the fasting plasma glucose level ( $\mathrm{mmol} / \mathrm{l}$ ) divided by $22 \cdot 5$. We established a diagnosis of insulin resistance when the fasting plasma insulin value was $\geq 15 \mathrm{mU} / 1$ or the HOMA index was $\geq 3 \cdot 8^{(12)}$ and when peak insulin after the OGTT was higher than $100 \mu \mathrm{U} / \mathrm{ml}$. Estimates of daily energy requirements were made using RMR calculated by the Harris-Benedict equation, and an activity factor of 1.5 was added to estimate total energy requirement. Daily energy intake for weight loss was calculated as the total energy requirement minus $4184 \mathrm{~kJ}(1000 \mathrm{kcal})$. The subjects were free living and asked to maintain their usual activity pattern. In each group, patients were randomized to follow either a $40 \%$ carbohydrate $/ 30 \%$ protein/30\% fat diet (diet A) or a 55\% carbohydrate/15\% protein/30\% fat diet (diet B). Random allocation to each diet group was generated by the main investigator (M.D.B.-P.) by using the website Randomization.com (http://www.randomization.com) on request of the study dietitian (A.R.C.-F.) after eligibility of a participant was confirmed and assignment to the insulin resistance group (IR or IS) had been made. The dietitian was responsible for giving individual counselling and written material to the participants in the initial visit; then the patients were instructed to record their food intake in a daily food diary and discussed it with the dietitian in their visit each two weeks. Medical assessment was blinded to the type of diet being undertaken. At the baseline visit, a physical examination including anthropometric measures (weight, height, BMI, waist circumference) and blood pressure was performed, and a $72 \mathrm{~h}$ dietary recall was done. Body composition was evaluated by means of a tetrapolar, single-frequency, bioelectrical impedance analyser (Holtain BC Analyser; Holtain, Crymych, UK) and a segmental hand-to-hand bioelectrical impedance analysis method (Omron BF 300; Omron Matsusaka Co. Ltd, Japan). The patients were evaluated every two weeks over a 16-week follow-up period. Evaluations included anthropometric measures, body composition and dietary recalls performed by the same dietitian. Baseline and final assessments also included a $75 \mathrm{~g}$ OGTT and blood samples for total cholesterol, HDL cholesterol, TAG, kidney and liver function tests, thyroid-stimulating hormone, Fe, ferritin and C-reactive protein. Dietary composition was analysed with the software Dietsource $2 \cdot 0$ (Novartis Consumer Health, Barcelona, Spain). Sample size was calculated by the Ene $2 \cdot 0$ software (http://www.e-biometria.com/ene-ctm/index.htm), following the results of studies by McLaughlin et al. ${ }^{(13)}$ and Cornier et $a l^{(11)}$, to detect a difference of 3-4 kg with $\beta=0.80$ and $\alpha=0 \cdot 05$. Change in body weight, the primary outcome analysed, was calculated as the body weight after 16 weeks on the hypoenergetic diet minus the weight at the baseline visit and expressed as absolute change in kilograms or as a percentage change from baseline. Descriptive data are presented as means and standard deviations, and also in graphical form as boxand-whisker plots including median value. Significance tests were two-sided, with significance set at $P<0 \cdot 05$. A Shapiro-Wilks test was performed to check whether or not quantitative data were normally distributed. The Pearson $\chi^{2}$ test and the independent-samples $t$ test were used (or the Mann-Whitney test if normality could not be assumed) to compare baseline characteristics and weight loss between groups (IR $v$. IS, diet A $v$. diet B). Repeatedmeasures ANOVA was performed to detect changes in HOMA, glucose, insulin and lipid profile and also to detect differences in dietary composition. The protocol of the study was approved by the Ethics and Clinical Investigation Committee of the Complejo Asistencial de León, and every participant gave informed consent. We certify that all applicable institutional and governmental regulations concerning the ethical use of human volunteers were followed during the research.

\section{Results}

\section{Patients' characteristics}

We included twenty-one IR and fifteen IS patients (Fig. 1), randomized to either diet A (40/30/30: ten IR, eight IS) or diet B (55/15/30: eleven IR, seven). Twenty-four were women (thirteen IR, eleven IS) and twelve men (eight IR, four IS). No significant differences were detected at the baseline visit in sex, age, weight or BMI in each diet group (A $v$. B: age, $40 \cdot 5$ (SD 13.4) $v .42 \cdot 7$ ( $\mathrm{SD} 14 \cdot 1)$ years, $P=0 \cdot 639$; initial weight, $89 \cdot 0$ (SD $12 \cdot 8) v \cdot 86 \cdot 6$ (SD $10 \cdot 8$ ) $\mathrm{kg}, P=0 \cdot 567$; BMI, $32 \cdot 8$ (sD 2.2) v. $32 \cdot 3(\mathrm{sD} 2 \cdot 3) \mathrm{kg} / \mathrm{m}^{2}$, $P=0.564)$ or regarding insulin sensitivity (IR $v$. IS: age $39 \cdot 8$ (SD 13.9) v. $44 \cdot 1$ (SD $13 \cdot 1$ ) years, $P=0 \cdot 349$; initial weight, $90 \cdot 3(\mathrm{sD} 13 \cdot 8) v \cdot 84 \cdot 2(\mathrm{sD} 7 \cdot 1) \mathrm{kg}, P=0 \cdot 105$; BMI, $32 \cdot 7$ (sD $\left.2 \cdot 1) v .32 \cdot 3(\mathrm{sD} 2 \cdot 5) \mathrm{kg} / \mathrm{m}^{2}, P=0.634\right)$. None of the baseline anthropometric and biochemical data were statistically different between groups (either IR $v$. IS or diet A $v$. diet B; Table 1) except for fasting and peak insulin levels $(P<0 \cdot 001)$ and HOMA index $(P<0 \cdot 05)$, which were higher in the IR group, in agreement with the inclusion criteria. This difference was between IR and IS, but in each insulin sensitivity group there was no difference between diet $\mathrm{A}$ and diet $\mathrm{B}$.

\section{Weight loss and changes in antbropometric and biochemical data}

After 16 weeks, no significant differences in weight loss with diet A or diet B (Table 2) were found in each sensitivity group. There were no differences between all subjects who were IR at baseline compared with those who were IS at baseline, or between all subjects on diet A compared with diet B. Insulin sensitivity was related neither to differences in weight loss nor to any other 


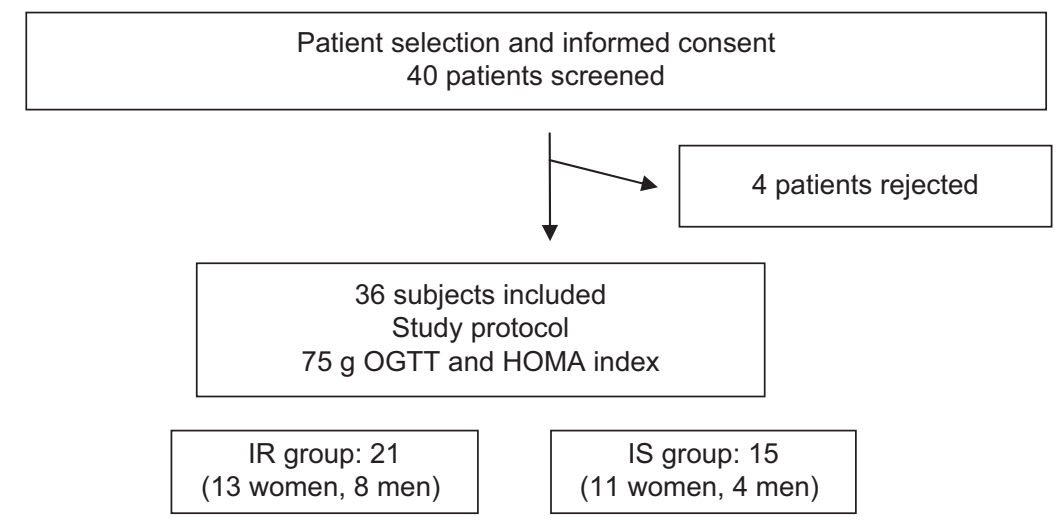

Randomization
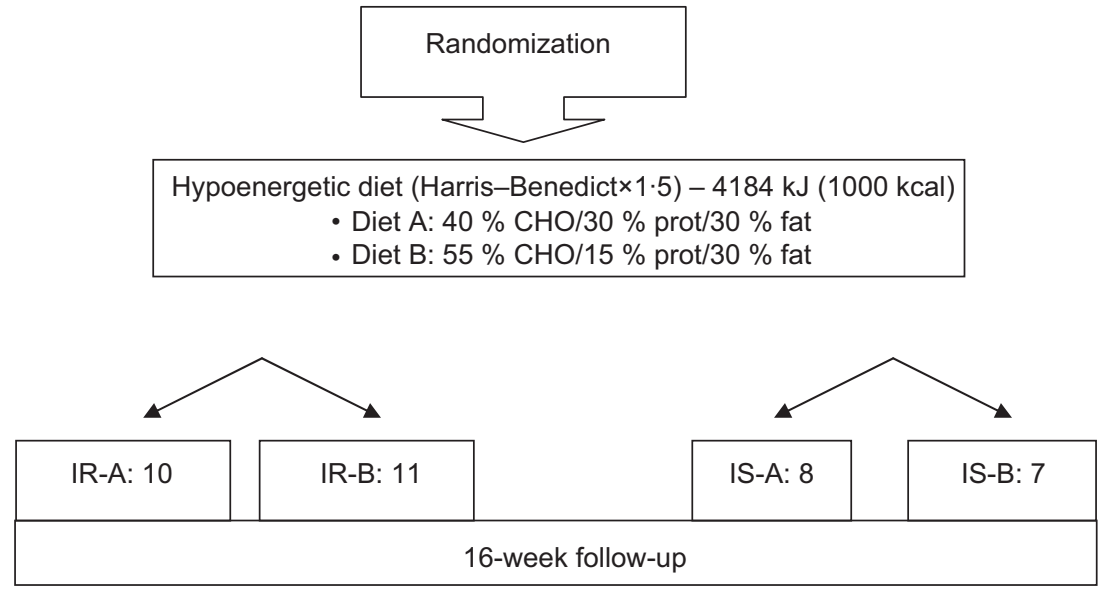

Fig. 1 Flow chart showing patient selection (OGTT, oral glucose tolerance test; HOMA, homeostasis model assessment of insulin resistance; $\mathrm{CHO}$, carbohydrate)

different outcome with different diet composition (Tables 2 and 3, Figs 2 and 3). Patients following the high-protein diet seemed to lose more body fat, although the difference was not statistically significant: $-5.4 v$. $-2.9 \mathrm{~kg}$ in the IR group and $-4.0 v .-1 \cdot 7 \mathrm{~kg}$ in the IS group. Fat-free mass losses were similar regardless of the type of diet but higher in the IS group $(-1.5 v,-1.8 \mathrm{~kg}$ in the IR group and $-4 \cdot 3 v .-5 \cdot 2 \mathrm{~kg}$ in the IS group; Table 3 ). Glucose and insulin levels and HOMA index at the initial visit were not significantly different in diet A or diet B; they were significantly reduced after weight loss at 16 weeks, but no differences related to the diet were detected in either the IR or the IS group (Table 3, Fig. 3).

\section{Changes in dietary composition}

No significant baseline differences in dietary composition were found between participants following diet A or diet B in each insulin sensitivity group (Table 4). Both diet groups reduced their energy intake significantly $(-2067 \mathrm{~kJ}(-494 \cdot 1 \mathrm{kcal})$ in the IR group $(P=0 \cdot 042)$ and $-1886 \mathrm{~kJ}(-450 \cdot 8 \mathrm{kcal})$ in the IS group $(P=0 \cdot 003))$ and, in accordance with the dietary changes recommended, at the end of the 16-week follow-up IR patients following diet A consumed a smaller percentage of carbohydrates
$(41.0 \% v .57 \cdot 4 \%, P=0 \cdot 001)$, more protein $(23 \cdot 8 \% v$. $16 \cdot 0 \%, P=0.003)$ and more fat $(35 \cdot 2 \% v .25 \cdot 1 \%$, $P=0 \cdot 012)$, including a higher intake of monounsaturated fat $(16 \cdot 0 \% v \cdot 10 \cdot 7 \%, P=0 \cdot 034)$, than those under diet $\mathrm{B}$. Over the 16-week period, IS individuals had fewer changes in their dietary composition than IR individuals, with only carbohydrate intake significantly changed (diet A $v$. diet $\mathrm{B}: 43 \cdot 3 \% v \cdot 51 \cdot 3 \%, P=0 \cdot 049)$. Those subjects following diet A did not change their diet composition very much, but those following diet $\mathrm{B}$ significantly reduced their energy intake by means of increasing the percentage of carbohydrates in the diet $(+17.4 \%$ in IR and $+19 \cdot 9 \%$ in IS) and reducing fat intake $(-14 \cdot 0 \%$ in IS, $-11 \cdot 2 \%$ in IR), especially saturated fat $(-6 \cdot 3 \%$ in IR and $-5 \cdot 3 \%$ in IS; Table 4). Individuals following diet A reported a non-statistically significant smaller energy deficit to achieve a similar weight loss, especially in the IR group (Table 5). Thus, weight loss was higher than expected in accordance to the energy restriction made for those individuals following diet A: $172 \%$ in the IR group and $146 \%$ in the IS group. To assess compliance, we studied the percentage of individuals who were achieving their prescribed diet composition goals in each group: $75.0 \%$ of the patients following diet A were consuming 
Table 1 Baseline characteristics of the participants: obese or overweight patients, Endocrinology Clinic, Complejo Asistencial de León, Spain

\begin{tabular}{|c|c|c|c|c|c|c|c|c|}
\hline & \multicolumn{4}{|c|}{ IR group } & \multicolumn{4}{|c|}{ IS group } \\
\hline & \multicolumn{2}{|c|}{ Diet A $(n 10)$} & \multicolumn{2}{|c|}{ Diet B (n 11) } & \multicolumn{2}{|c|}{ Diet A $(n 8)$} & \multicolumn{2}{|c|}{ Diet $\mathrm{B}(n 7)$} \\
\hline & Mean & SD & Mean & SD & Mean & SD & Mean & SD \\
\hline Age (years) & $36 \cdot 4$ & $12 \cdot 6$ & $44 \cdot 0$ & $14 \cdot 4$ & $47 \cdot 3$ & $11 \cdot 8$ & $40 \cdot 6$ & $14 \cdot 5$ \\
\hline Body weight (kg) & $93 \cdot 0$ & $14 \cdot 3$ & $88 \cdot 0$ & $12 \cdot 0$ & $85 \cdot 4$ & $8 \cdot 4$ & $85 \cdot 6$ & $8 \cdot 8$ \\
\hline Height $(\mathrm{cm})$ & $168 \cdot 3$ & $11 \cdot 3$ & $162 \cdot 8$ & $9 \cdot 8$ & $161 \cdot 0$ & $9 \cdot 7$ & $164 \cdot 9$ & $6 \cdot 5$ \\
\hline BMI $\left(\mathrm{kg} / \mathrm{m}^{2}\right)$ & $32 \cdot 7$ & $1 \cdot 9$ & $32 \cdot 9$ & $2 \cdot 2$ & $32 \cdot 5$ & $1 \cdot 9$ & $32 \cdot 8$ & $2 \cdot 3$ \\
\hline Waist circumference $(\mathrm{cm})$ & $103 \cdot 4$ & $7 \cdot 3$ & $105 \cdot 9$ & $9 \cdot 2$ & $105 \cdot 8$ & $6 \cdot 3$ & $98 \cdot 5$ & 4.9 \\
\hline Hip circumference $(\mathrm{cm})$ & $111 \cdot 3$ & $8 \cdot 0$ & $114 \cdot 0$ & $8 \cdot 8$ & $114 \cdot 0$ & $4 \cdot 4$ & $110 \cdot 1$ & $4 \cdot 5$ \\
\hline RMR (Harris-Benedict) (kJ/d) & 7409 & 1636 & 6958 & 1071 & 6581 & 959 & 7132 & 1183 \\
\hline RMR (Harris-Benedict) (kcal/d) & $1770 \cdot 8$ & $390 \cdot 9$ & $1662 \cdot 9$ & $255 \cdot 9$ & $1572 \cdot 8$ & $229 \cdot 3$ & $1704 \cdot 6$ & $282 \cdot 8$ \\
\hline Systolic blood pressure (mmHg) & $127 \cdot 1$ & $18 \cdot 0$ & $123 \cdot 0$ & $16 \cdot 4$ & $126 \cdot 7$ & $20 \cdot 8$ & $132 \cdot 5$ & $16 \cdot 7$ \\
\hline Diastolic blood pressure (mmHg) & $78 \cdot 5$ & $14 \cdot 9$ & $76 \cdot 0$ & $8 \cdot 9$ & $83 \cdot 3$ & $10 \cdot 4$ & $82 \cdot 5$ & $15 \cdot 4$ \\
\hline Fat mass $(\%)$ & $31 \cdot 4$ & $8 \cdot 2$ & $35 \cdot 2$ & $10 \cdot 4$ & $37 \cdot 5$ & $4 \cdot 8$ & $31 \cdot 9$ & $5 \cdot 8$ \\
\hline Fat-free mass (\%) & $64 \cdot 2$ & $14 \cdot 1$ & $56 \cdot 7$ & $11 \cdot 1$ & $53 \cdot 8$ & $9 \cdot 2$ & $58 \cdot 6$ & $10 \cdot 6$ \\
\hline Glucose $(\mathrm{mg} / \mathrm{dl})$ & $88 \cdot 4$ & $13 \cdot 5$ & $91 \cdot 9$ & $13 \cdot 6$ & $84 \cdot 6$ & $11 \cdot 4$ & $80 \cdot 7$ & 6.9 \\
\hline Fasting insulin $(\mu \mathrm{U} / \mathrm{ml})$ & $20 \cdot 9$ & $6 \cdot 1$ & $38 \cdot 2$ & $51 \cdot 8$ & $9 \cdot 5 t$ & $2 \cdot 3$ & $9 \cdot 2 \dagger$ & $3 \cdot 2$ \\
\hline Peak insulin $(\mu \mathrm{U} / \mathrm{ml})$ & $152 \cdot 4$ & $169 \cdot 8$ & $128 \cdot 2$ & $58 \cdot 8$ & $67 \cdot 5+$ & $25 \cdot 5$ & $58 \cdot 0+$ & $23 \cdot 7$ \\
\hline HOMA index & 4.5 & $1 \cdot 1$ & $5 \cdot 1$ & $3 \cdot 2$ & $2 \cdot 0^{*}$ & 0.5 & $1 \cdot 8^{\star}$ & 0.5 \\
\hline AST (U/l) & $27 \cdot 3$ & $10 \cdot 7$ & $23 \cdot 7$ & $13 \cdot 9$ & $22 \cdot 6$ & $11 \cdot 0$ & $20 \cdot 9$ & $7 \cdot 4$ \\
\hline $\operatorname{ALT}(U / I)$ & $43 \cdot 1$ & $32 \cdot 9$ & $37 \cdot 1$ & $32 \cdot 9$ & $30 \cdot 3$ & $26 \cdot 5$ & $26 \cdot 7$ & $11 \cdot 7$ \\
\hline Total cholesterol (mg/dl) & $196 \cdot 6$ & $31 \cdot 0$ & $201 \cdot 5$ & $29 \cdot 7$ & $224 \cdot 4$ & $39 \cdot 0$ & $210 \cdot 3$ & $35 \cdot 3$ \\
\hline TAG $(\mathrm{mg} / \mathrm{dl})$ & $134 \cdot 9$ & $71 \cdot 5$ & $157 \cdot 2$ & $60 \cdot 8$ & $161 \cdot 9$ & $142 \cdot 2$ & $139 \cdot 6$ & $59 \cdot 3$ \\
\hline HDL cholesterol (mg/dl) & $50 \cdot 6$ & $14 \cdot 2$ & $49 \cdot 9$ & $11 \cdot 9$ & $59 \cdot 9$ & $21 \cdot 3$ & $57 \cdot 1$ & $19 \cdot 3$ \\
\hline LDL cholesterol (mg/dl) & $119 \cdot 0$ & $26 \cdot 7$ & $118 \cdot 3$ & $28 \cdot 4$ & $125 \cdot 9$ & $22 \cdot 8$ & $125 \cdot 2$ & $28 \cdot 7$ \\
\hline C-reactive protein (mg/dl) & 1.5 & $0 \cdot 7$ & $4 \cdot 2$ & $3 \cdot 0$ & $4 \cdot 0$ & $1 \cdot 3$ & $2 \cdot 0$ & $0 \cdot 8$ \\
\hline
\end{tabular}

HOMA, homeostasis model assessment of insulin resistance; AST, aspartate aminotransferase; ALT, alanine aminotransferase.

A $t$ test was used to compare the means of subjects assigned to diet A and diet B within each insulin sensitivity group (IR, insulin-resistant; IS, insulin-sensitive); there were no significant differences. In addition, a $t$ test was used to compare the means of the IR and IS groups; there were no significant differences except for ${ }^{*} P=0.000$ between IR and IS groups; $+P=0.04$ between IR and IS groups.

Table 2 Changes in body weight $(\mathrm{kg})$ from baseline in insulin-resistant (IR) and insulin-sensitive (IS) groups on diet A and diet B having different protein:carbohydrate ratios: obese or overweight patients, Endocrinology Clinic, Complejo Asistencial de León, Spain

\begin{tabular}{|c|c|c|c|c|c|c|c|c|}
\hline & \multicolumn{4}{|c|}{ IR group } & \multicolumn{4}{|c|}{ IS group } \\
\hline & \multicolumn{2}{|c|}{ Diet A } & \multicolumn{2}{|c|}{ Diet B } & \multicolumn{2}{|c|}{ Diet A } & \multicolumn{2}{|c|}{ Diet B } \\
\hline & Mean & SD & Mean & SD & Mean & SD & Mean & SD \\
\hline Week 2 & $-2 \cdot 6$ & $1 \cdot 6$ & $-1 \cdot 9$ & $1 \cdot 6$ & $-2 \cdot 7$ & 0.9 & $-2 \cdot 4$ & $1 \cdot 6$ \\
\hline Week 4 & $-4 \cdot 2$ & $2 \cdot 3$ & $-3 \cdot 5$ & $2 \cdot 3$ & $-4 \cdot 1$ & $1 \cdot 3$ & $-4 \cdot 2$ & $1 \cdot 6$ \\
\hline Week 6 & $-5 \cdot 6$ & $2 \cdot 7$ & $-4 \cdot 3$ & $3 \cdot 0$ & $-5 \cdot 2$ & $1 \cdot 8$ & $-4 \cdot 9$ & $2 \cdot 0$ \\
\hline Week 8 & $-7 \cdot 1$ & $3 \cdot 3$ & $-5 \cdot 4$ & $2 \cdot 9$ & $-5 \cdot 9$ & $2 \cdot 7$ & $-6 \cdot 3$ & $1 \cdot 2$ \\
\hline Week 10 & $-7 \cdot 9$ & $4 \cdot 1$ & $-5 \cdot 8$ & $3 \cdot 6$ & $-6 \cdot 9$ & $2 \cdot 8$ & $-7 \cdot 2$ & $2 \cdot 1$ \\
\hline Week 12 & $-8 \cdot 4$ & $4 \cdot 2$ & $-5 \cdot 7$ & $3 \cdot 5$ & $-7 \cdot 3$ & $3 \cdot 2$ & $-7 \cdot 5$ & $1 \cdot 9$ \\
\hline Week 14 & $-9 \cdot 0$ & $4 \cdot 8$ & $-7 \cdot 6$ & $4 \cdot 8$ & $-8 \cdot 7$ & $3 \cdot 7$ & $-7 \cdot 9$ & $2 \cdot 4$ \\
\hline Week 16 & $-9 \cdot 3$ & $6 \cdot 3$ & $-6 \cdot 7$ & $4 \cdot 9$ & $-8 \cdot 6$ & $4 \cdot 8$ & $-7 \cdot 9$ & $3 \cdot 0$ \\
\hline
\end{tabular}

There were no significant differences between groups.

less than $40 \%$ of energy as carbohydrates, and $86.7 \%$ of those following diet B were consuming more than $50 \%$ as carbohydrates.

\section{Discussion}

Achieving successful weight loss requires significant reductions in energy intake relative to energy expenditure. Nevertheless, physiological metabolic differences could play a role in different responses to different types of diet. Glycaemic status does not seem to play a sig- nificant role for weight loss according to previous reports $^{(14)}$. Insulin sensitivity state in response to an energy-restricted diet did not affect weight loss in obese individuals in our study, as has been previously reported $^{(13,15,16)}$. Cornier et al. ${ }^{(11)}$, however, reported that obese insulin-sensitive women had a better response to a high-carbohydrate/low-fat (60\% carbohydrate/20\% protein $/ 20 \%$ fat) diet than to a low-carbohydrate/high-fat diet ( $40 \%$ carbohydrate $/ 20 \%$ protein/ $40 \%$ fat; weight loss of $13.5 \% v \cdot 6 \cdot 8 \%, P=0.002$ between the groups), while insulin-resistant women lost more weight on the lowcarbohydrate/high-fat diet $(8.5 \% \quad v .13 .4 \%, \quad P=0.04$ 
Table 3 Anthropometric and biochemical data at baseline and week 16 in insulin-resistant (IR) and insulin-sensitive (IS) groups on diet A and diet B having different protein:carbohydrate ratios: obese or overweight patients, Endocrinology Clinic, Complejo Asistencial de León, Spain

\begin{tabular}{|c|c|c|c|c|c|c|c|c|c|c|c|c|c|c|c|}
\hline & \multicolumn{8}{|c|}{ IR group } & \multicolumn{7}{|c|}{ IS group } \\
\hline & \multicolumn{4}{|c|}{ Diet A } & \multicolumn{4}{|c|}{ Diet B } & \multicolumn{4}{|c|}{ Diet A } & \multicolumn{3}{|c|}{ Diet B } \\
\hline & \multicolumn{2}{|c|}{ Baseline } & \multicolumn{2}{|c|}{ After 16 weeks } & \multicolumn{2}{|c|}{ Baseline } & \multicolumn{2}{|c|}{ After 16 weeks } & \multicolumn{2}{|c|}{ Baseline } & \multicolumn{2}{|c|}{ After 16 weeks } & Baseline & \multicolumn{2}{|c|}{ After 16 weeks } \\
\hline & Mean & SD & Mean & SD & Mean & SD & Mean & SD & Mean & SD & Mean & SD & Mean SD & Mean & SD \\
\hline Body weight (kg) & $93 \cdot 0$ & $14 \cdot 3$ & $85 \cdot 1$ & $15 \cdot 2$ & $88 \cdot 0$ & $12 \cdot 0$ & $79 \cdot 9$ & $14 \cdot 1$ & $85 \cdot 4$ & $8 \cdot 4$ & $74 \cdot 3$ & $7 \cdot 4$ & $85 \cdot 6 \quad 8 \cdot 8$ & $76 \cdot 3$ & $7 \cdot 9$ \\
\hline BMI $\left(\mathrm{kg} / \mathrm{m}^{2}\right)$ & $32 \cdot 7$ & $1 \cdot 9$ & $29 \cdot 5$ & $3 \cdot 1$ & $32 \cdot 9$ & $2 \cdot 2$ & $30 \cdot 4$ & $2 \cdot 9$ & $32 \cdot 5$ & $1 \cdot 9$ & $29 \cdot 4$ & $2 \cdot 9$ & $32 \cdot 8 \quad 2 \cdot 3$ & $28 \cdot 5$ & $2 \cdot 3$ \\
\hline Waist circumference $(\mathrm{cm})$ & $103 \cdot 4$ & $7 \cdot 3$ & $99 \cdot 1$ & $11 \cdot 0$ & $105 \cdot 9$ & $9 \cdot 2$ & $96 \cdot 8$ & $9 \cdot 5$ & $105 \cdot 8$ & $6 \cdot 3$ & $97 \cdot 3$ & $7 \cdot 4$ & $98.5 \quad 4.9$ & $93 \cdot 3$ & $6 \cdot 2$ \\
\hline Hip circumference $(\mathrm{cm})$ & $111 \cdot 3$ & $8 \cdot 0$ & $105 \cdot 6$ & $6 \cdot 1$ & $114 \cdot 0$ & $8 \cdot 8$ & $106 \cdot 5$ & $7 \cdot 4$ & $114 \cdot 0$ & $4 \cdot 4$ & $106 \cdot 1$ & $5 \cdot 9$ & $110 \cdot 1 \quad 4 \cdot 5$ & $104 \cdot 3$ & $6 \cdot 2$ \\
\hline Fat mass (\%) & $31 \cdot 4$ & $8 \cdot 2$ & $26 \cdot 0$ & $10 \cdot 2$ & $35 \cdot 2$ & $10 \cdot 4$ & $32 \cdot 3$ & $10 \cdot 3$ & $37 \cdot 5$ & $4 \cdot 8$ & 33.5 & $2 \cdot 1$ & $31.9 \quad 5 \cdot 8$ & $30 \cdot 2$ & $8 \cdot 1$ \\
\hline Fat-free mass (\%) & $64 \cdot 2$ & $14 \cdot 1$ & $62 \cdot 7$ & $13 \cdot 1$ & $56 \cdot 7$ & $11 \cdot 1$ & $54 \cdot 9$ & $15 \cdot 3$ & $53 \cdot 8$ & $9 \cdot 2$ & $49 \cdot 5$ & $4 \cdot 7$ & $58 \cdot 610 \cdot 6$ & $53 \cdot 4$ & $8 \cdot 7$ \\
\hline$(\mathrm{mg} / \mathrm{dl})$ & $88 \cdot 4$ & $13 \cdot 5$ & $81 \cdot 8$ & $8 \cdot 3$ & $91 \cdot 9$ & $13 \cdot 6$ & $82 \cdot 1$ & $11 \cdot 3$ & $84 \cdot 6$ & $11 \cdot 4$ & $80 \cdot 3$ & $8 \cdot 1$ & $80.7 \quad 6.9$ & $80 \cdot 0$ & $7 \cdot 0$ \\
\hline insulin $(\mu \mathrm{U} / \mathrm{ml})$ & $20 \cdot 9$ & $6 \cdot 1$ & $13 \cdot 4$ & $10 \cdot 1$ & $38 \cdot 2$ & $51 \cdot 8$ & $12 \cdot 5$ & $7 \cdot 8$ & $9 \cdot 5$ & $2 \cdot 3$ & $8 \cdot 0$ & $5 \cdot 0$ & $9 \cdot 2 \quad 3 \cdot 2$ & $6 \cdot 7$ & $2 \cdot 1$ \\
\hline Peak insulin $(\mu \mathrm{U} / \mathrm{ml})$ & $152 \cdot 4$ & $169 \cdot 8$ & $76 \cdot 4$ & $58 \cdot 8$ & $128 \cdot 2$ & $58 \cdot 8$ & $76 \cdot 3$ & $58 \cdot 0$ & $67 \cdot 5$ & $25 \cdot 5$ & $55 \cdot 6$ & $42 \cdot 0$ & $58 \cdot 023 \cdot 7$ & $51 \cdot 2$ & $24 \cdot 0$ \\
\hline HOMA index & $4 \cdot 5$ & $1 \cdot 1$ & $2 \cdot 7$ & $2 \cdot 1$ & $5 \cdot 1$ & $3 \cdot 2$ & $2 \cdot 6$ & $1 \cdot 8$ & $2 \cdot 0$ & 0.5 & $1 \cdot 7$ & 0.9 & $1.8 \quad 0.5$ & $1 \cdot 2$ & $0 \cdot 3$ \\
\hline AST (U/I) & $27 \cdot 3$ & $10 \cdot 7$ & $21 \cdot 3$ & $6 \cdot 0$ & $23 \cdot 7$ & 13.9 & $20 \cdot 9$ & $8 \cdot 7$ & $22 \cdot 6$ & $11 \cdot 0$ & $19 \cdot 1$ & $2 \cdot 5$ & $20 \cdot 9 \quad 7 \cdot 4$ & $17 \cdot 0$ & $5 \cdot 2$ \\
\hline $\operatorname{ALT}(U / I)$ & $43 \cdot 1$ & $32 \cdot 9$ & $36 \cdot 1$ & $25 \cdot 9$ & $37 \cdot 1$ & $32 \cdot 9$ & $21 \cdot 3$ & $8 \cdot 7$ & $30 \cdot 3$ & $26 \cdot 5$ & $19 \cdot 9$ & $7 \cdot 0$ & $26 \cdot 711 \cdot 7$ & $20 \cdot 3$ & $6 \cdot 7$ \\
\hline Total cholesterol (mg/dl) & $196 \cdot 6$ & $31 \cdot 0$ & $157 \cdot 3$ & $33 \cdot 4$ & $201 \cdot 5$ & $29 \cdot 7$ & $190 \cdot 0$ & $43 \cdot 4$ & $224 \cdot 4$ & $39 \cdot 0$ & $190 \cdot 9$ & $48 \cdot 2$ & $210 \cdot 335 \cdot 3$ & $192 \cdot 3$ & $26 \cdot 0$ \\
\hline TAG (mg/dl) & $134 \cdot 9$ & $71 \cdot 5$ & $96 \cdot 8$ & $47 \cdot 3$ & $157 \cdot 2$ & $260 \cdot 8$ & $119 \cdot 3$ & $52 \cdot 2$ & $161 \cdot 9$ & $142 \cdot 2$ & $82 \cdot 6$ & $19 \cdot 7$ & $139 \cdot 659 \cdot 3$ & $125 \cdot 0$ & $75 \cdot 3$ \\
\hline HDL cholesterol (mg/dl) & $50 \cdot 6$ & $14 \cdot 2$ & $44 \cdot 2$ & $12 \cdot 7$ & $49 \cdot 9$ & 11.9 & $49 \cdot 3$ & $12 \cdot 4$ & $59 \cdot 9$ & $21 \cdot 3$ & $62 \cdot 0$ & $17 \cdot 9$ & $57 \cdot 119 \cdot 3$ & $59 \cdot 7$ & $15 \cdot 1$ \\
\hline LDL cholesterol (mg/dl) & $119 \cdot 0$ & $26 \cdot 7$ & $93 \cdot 8$ & $28 \cdot 8$ & $118 \cdot 3$ & $28 \cdot 4$ & $116 \cdot 9$ & $34 \cdot 9$ & $125 \cdot 9$ & $22 \cdot 8$ & $112 \cdot 4$ & $41 \cdot 3$ & $125 \cdot 228 \cdot 7$ & $107 \cdot 8$ & $26 \cdot 5$ \\
\hline C-reactive protein $(\mathrm{mg} / \mathrm{dl})$ & 1.5 & $0 \cdot 7$ & $2 \cdot 0$ & $1 \cdot 2$ & $4 \cdot 2$ & 3.0 & $2 \cdot 2$ & 0.9 & $4 \cdot 0$ & $1 \cdot 3$ & $4 \cdot 4$ & $1 \cdot 6$ & $2 \cdot 0 \quad 0 \cdot 8$ & $2 \cdot 4$ & $1 \cdot 8$ \\
\hline
\end{tabular}

HOMA, homeostasis model assessment of insulin resistance; AST, aspartate aminotransferase; ALT, alanine aminotransferase.

No significant differences between diet $A$ and $B$ in each insulin sensitivity group (IR or IS).
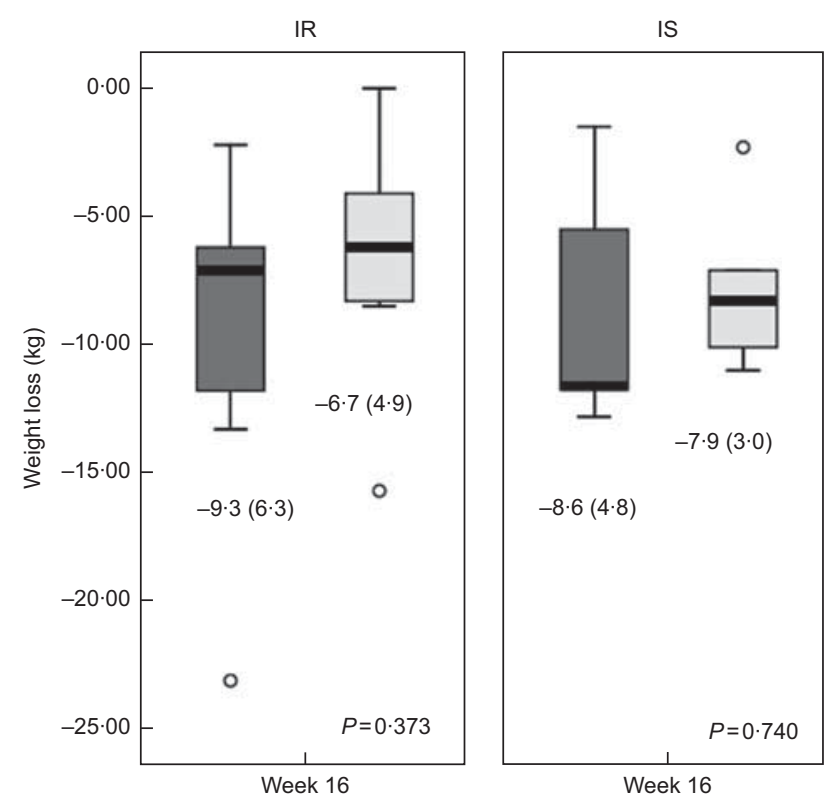

Fig. 2 Box-and-whisker plots of weight loss, and mean (standard deviation), in insulin-resistant (IR) and insulinsensitive (IS) groups after 16 weeks on diet $A(\square)$ or diet B $(\square)$ having different protein:carbohydrate ratios: obese or overweight patients (BMI $28-35 \mathrm{~kg} / \mathrm{m}^{2}$, aged $18-70$ years), Endocrinology Clinic, Complejo Asistencial de León, Spain

between the two groups). They hypothesized that if insulin promotes better use of dietary carbohydrates in IS individuals, perhaps through increased dietary-induced and/or cellular thermogenesis compared with IR individuals, a high-carbohydrate diet would involve a greater
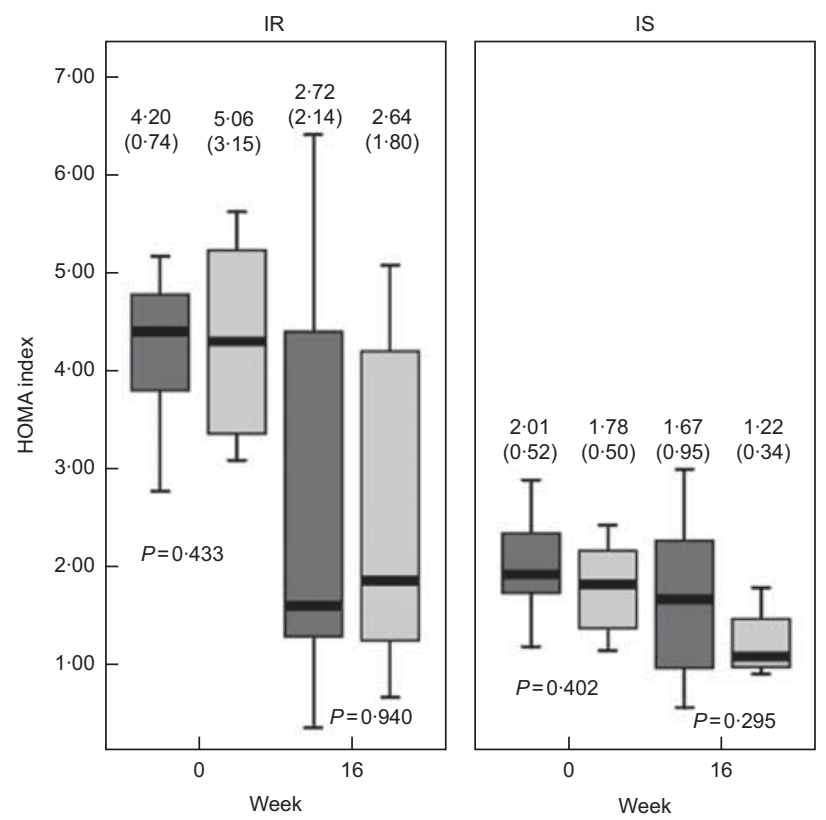

Fig. 3 Box-and-whisker plots of changes in insulin sensitivity from baseline according to homeostasis model assessment of insulin resistance (HOMA) index, and mean (standard deviation), in insulin-resistant (IR) and insulin-sensitive (IS) groups after 16 weeks on diet $A(\square)$ or diet $B(\square)$ having different protein:carbohydrate ratios: obese or overweight patients (BMI $28-35 \mathrm{~kg} / \mathrm{m}^{2}$, aged $18-70$ years), Endocrinology Clinic, Complejo Asistencial de León, Spain

weight loss. Likewise, they hypothesized that IR individuals would have a better response to a low-carbohydrate/high-protein hypoenergetic diet. Noakes et $a l^{(17)}$ 
also reported that an energy-restricted diet with a high ratio of protein to carbohydrate provided a weight loss advantage in subjects with elevated TAG concentrations, a marker useful in identifying insulin resistance ${ }^{(18)}$. In contrast, McLaughlin et al. ${ }^{(19)}$ reported that weight loss with $60 \%$ carbohydrate $/ 25 \%$ fat or $40 \%$ carbohydrate/ $40 \%$ fat, with $15 \%$ protein in both cases, did not significantly differ in insulin-resistant women $(5.7$ (SD 0.7$) \mathrm{kg}$ or 6.9 (SD 0.7$) \mathrm{kg}$, respectively). Our results for weight loss correspond with this last study, although the diet composition was not exactly the same. In both Cornier's and McLaughlin's studies, all study subjects were women, and dietary protein intake was maintained in both groups at $15-20 \%$. Moreover, food was prepared by the investigators in Cornier's study, while our patients, and McLaughlin's, were given the needed recipes but prepared their own food in a real-life scenario. Our concerns about the long-term impact of high-fat diets compelled us to change the macronutrient composition for the study in an attempt to achieve a moderate-fat diet (30\% of energy) and to change the ratio of protein to carbohydrate: $30 / 40$ for diet A and 15/55 for diet B. McLaughlin's study, like ours, reported that obese, insulin-resistant persons achieve similar weight loss when they follow energyrestricted diets with moderate reductions in dietary carbohydrate, contradicting Cornier's study.

In spite of a similar weight loss with a different protein:carbohydrate ratio, our patients following the highprotein diet seemed to lose more body fat, although the difference was not statistically significant $(P=0.457$ in IR and $P=0.06$ in IS). Fat-free mass losses were similar despite the type of diet but higher in the IS group. These findings corroborate those of Laymen et al. ${ }^{(20)}$, emphasizing the metabolic effects of a high-protein diet under isoenergetic conditions. They found an improved body composition due to a higher ratio of dietary protein to carbohydrate, but weight loss on the high-protein diet was not different from that in the control group, probably due to lack of difference in energy intake. In studies comparing a low-carbohydrate diet with ad libitum energy intake and a conventional energy-restricted lowfat $\operatorname{diet}^{(6)}$, fat mass also decreased significantly more in the low-carbohydrate/high-protein group. Although in McLaughlin et al.'s study ${ }^{(19)}$ several CVD risk factors (daylong insulin concentrations, lipid and lipoprotein concentrations and cellular adhesion molecules) improved significantly in the subjects following the $40 \%$ carbohydrate diet without any difference in weight loss, no significant differences between $\operatorname{diet} \mathrm{A}$ and $\operatorname{diet} \mathrm{B}$ in each insulin sensitivity group (IR or IS) were found in our study. IR subjects had decreased TAG $(-38 \cdot 1 \mathrm{mg} / \mathrm{dl}$ with the $30 / 40$ diet, $-37.9 \mathrm{mg} / \mathrm{dl}$ with the $15 / 55$ diet), LDL cholesterol $(-25 \cdot 2 \mathrm{mg} / \mathrm{dl}$ with the $30 / 40 \mathrm{diet},-1 \cdot 4 \mathrm{mg} / \mathrm{dl}$ with the $15 / 55$ diet) and, unfortunately, HDL cholesterol $(-6.4 \mathrm{mg} / \mathrm{dl}$ with the $30 / 40 \mathrm{diet},-0.6 \mathrm{mg} / \mathrm{dl}$ with the $15 / 55$ diet), as did insulin-sensitive patients (30/40 diet $v$. 
Table 5 Energy deficit and weight loss in insulin-resistant (IR) and insulin-sensitive (IS) groups on diet A and diet B having different protein:carbohydrate ratios: obese or overweight patients, Endocrinology Clinic, Complejo Asistencial de León, Spain

\begin{tabular}{|c|c|c|c|c|c|c|c|c|}
\hline & \multicolumn{4}{|c|}{ IR group } & \multicolumn{4}{|c|}{ IS group } \\
\hline & \multicolumn{2}{|c|}{ Diet A } & \multicolumn{2}{|c|}{ Diet B } & \multicolumn{2}{|c|}{ Diet A } & \multicolumn{2}{|c|}{ Diet B } \\
\hline & Mean & SD & Mean & SD & Mean & SD & Mean & SD \\
\hline Observed weight change (kg) & $-9 \cdot 3$ & $6 \cdot 3$ & $-6 \cdot 7$ & 4.9 & $-8 \cdot 6$ & $4 \cdot 8$ & $-7 \cdot 9$ & $3 \cdot 0$ \\
\hline Observed energy deficit (kJ/d) & -1480 & 1233 & -2823 & 1215 & -1599 & 843 & -2174 & 613 \\
\hline Observed energy deficit (kcal/d) & $-353 \cdot 7$ & $294 \cdot 7$ & $-674 \cdot 7$ & $290 \cdot 5$ & $-382 \cdot 1$ & $201 \cdot 4$ & $-519 \cdot 6$ & $146 \cdot 5$ \\
\hline $\mathrm{kJ} / \mathrm{d}$ deficit/kg weight loss & 159 & 231 & 421 & 209 & 186 & 128 & 275 & 216 \\
\hline $\mathrm{kcal} / \mathrm{d}$ deficit/kg weight loss & $38 \cdot 0$ & $55 \cdot 2$ & $100 \cdot 7$ & $50 \cdot 0$ & $44 \cdot 4$ & $30 \cdot 5$ & $65 \cdot 7$ & $51 \cdot 7$ \\
\hline Expected weight change according to energy deficit $(\mathrm{kg})$ & \multirow{2}{*}{\multicolumn{2}{|c|}{$\begin{array}{c}-5 \cdot 4 \\
172\end{array}$}} & \multirow{2}{*}{\multicolumn{2}{|c|}{$\begin{array}{c}-10 \cdot 4 \\
64\end{array}$}} & \multirow{2}{*}{\multicolumn{2}{|c|}{$\begin{array}{c}-5.9 \\
146\end{array}$}} & \multirow{2}{*}{\multicolumn{2}{|c|}{$\begin{array}{c}-7 \cdot 8 \\
101\end{array}$}} \\
\hline$\%$ observed/expected weight loss & & & & & & & & \\
\hline
\end{tabular}

15/55 diet: TAG, $-79 \cdot 3 v$. $-14 \cdot 6 \mathrm{mg} / \mathrm{dl}$; LDL cholesterol, $-13.5 v .-17 \cdot 4 \mathrm{mg} / \mathrm{dl})$. The exception to this was HDL cholesterol $(+2 \cdot 1 \quad v \cdot+2 \cdot 6 \mathrm{mg} / \mathrm{dl})$, but differences were not significant.

High-protein diets appear to imply higher thermogenesis, which contributes to the low energy efficiency of protein during body weight loss and weight regain ${ }^{(21)}$. Replacement of some dietary carbohydrates by protein ( $25 \% v .12 \%$ energy intake from protein) in an ad libitum fat-reduced diet have previously been shown to induce a greater weight loss $(8.9 v .5 \cdot 1 \mathrm{~kg})$ due to a lower energy intake $(5000 \mathrm{~kJ} / \mathrm{d}(1195 \mathrm{kcal} / \mathrm{d}) \quad v .6201 \mathrm{~kJ} / \mathrm{d}(1482 \mathrm{kcal} /$ d) $)^{(22)}$. Another study also confirmed these findings but, when compared with an isoenergetic high-carbohydrate diet, high-protein diets did not imply a significant difference in body weight loss ${ }^{(23)}$. It has been reported that $1 \mathrm{~kg}$ of weight loss translates into an energy deficit of $30.5 \mathrm{MJ}(7300 \mathrm{kcal})$ in women ${ }^{(24)}$. In the study by Cornier et $a l^{(11)}$, a weight loss of $6 \cdot 1 \mathrm{~kg}(187 \mathrm{MJ}(44800 \mathrm{kcal})$ deficit $/ 30 \cdot 5 \mathrm{MJ}(7300 \mathrm{kcal})$ deficit $)$ was expected, but the actual weight loss in IR individuals on the low-carbohydrate/high-fat diet and the IS individuals on the highcarbohydrate/low-fat diet was higher than anticipated. Dietary recalls, however, revealed no differences in energy intake, suggesting a different metabolic role of protein in accordance with insulin sensitivity, but these findings have not been corroborated by our study. We did not find differences regarding the insulin sensitivity state, but weight loss was higher than expected in accordance to the energy restriction made for those individuals following diet A: $172 \%$ in the IR group and $146 \%$ in the IS group (Table 5). The large differences between the expected weight loss and actual weight loss also could point to problems with the self-report of diet and/or changes in physical activity, but the reported energy deficit did not predict weight loss on an individual level. No significant relationship was found between energy deficit and weight loss (non-significant Pearson correlation). We suggest that better energy efficiency of a diet with a higher protein:carbohydrate ratio entails similar weight loss with less effort, but more studies are needed since we did not see a significant difference.
Our study has several limitations that should be discussed before reaching any conclusions. First, although sample size was calculated following the results of previous studies $^{(11,13)}$, the number of subjects per group was small. This fact implies we could not reach statistical significance in secondary endpoints, such as dietary changes. The study was carried out in just one service, so perhaps this fact does not allow that the results may be generalized. Third, the experimental dietary intervention was carried out in the short term, only 16 weeks, so we cannot exclude differences with a longer intervention and/or follow-up period. Moreover, the study was performed in a free-living scenario, which sets up the problem of compliance. This way, people under diet B had a greater energy deficit, although their weight loss was similar to those individuals following diet A. In any case, we should not forget that obesity treatment involves changes in the patient's lifestyle, and changing dietary patterns artificially would probably not be effective in the long term. In spite of dietary recalls performed, we cannot rule out non-compliance. We agree that compliance is a major concern in this study. We did not ask our patients about palatability, which would have been a good idea to see the influence in compliance. Another conflicting point is that, as energy expenditure or the thermic effect of feeding was not measured, we cannot be certain that the differences in weight loss among the groups were not due to greater activity or feeding thermogenesis. Also, the way to assess insulin sensitivity is still under debate ${ }^{(25-27)}$. We classified patients after an OGTT, taking into account both baseline fasting insulin/HOMA index and peak insulin. Studies following either of these approaches can be found. For example, Cornier et $a l^{(11)}$ chose fasting insulin and demonstrated a strong correlation between fasting insulinaemia and the Si index, as determined by Bergman's minimal model, in individuals with insulin levels below 10 and above $15 \mu \mathrm{U} / \mathrm{ml}(r=0 \cdot 50, P<0 \cdot 05)$, while in the more recent study by Ebbeling et al. ${ }^{(28)}$ peak insulin was preferred.

In conclusion, macronutrient composition of a hypoenergetic diet, specifically the percentage protein:carbohydrate ratio, did not produce differential weight loss or 
improvement in insulin sensitivity in our obese people, irrespective of their state of insulin sensitivity. More favourable changes in weight loss or body composition in individuals following a diet with a greater protein:carbohydrate ratio have yet to be determined.

\section{Acknowledgements}

This research received no specific grant from any funding agency in the public, commercial or not-for-profit sectors. No conflict of interests needs to be reported. Every author has contributed sufficiently, intellectually or practically, to the paper in the following items: (i) the conception and design of the study, or acquisition of data, or analysis and interpretation of data; (ii) drafting the article or revising it critically for important intellectual content; and (iii) final approval of the version to be submitted. Everyone has given permission for their name to be included as a co-author after reading and approving the final version submitted. M.D.B.-P. conceived the study, carried out the studies, performed the statistical analysis and drafted the manuscript. A.R.C.-F. carried out the anthropometric and dietary studies, participated in the design and coordination of the study and helped to draft the manuscript. A.V.-C. and A.M.U.-F. participated in the design of the study. I.C.-R. conceived the study and participated in its design and coordination.

\section{References}

1. World Health Organization (2000) Obesity: Preventing and Managing the Global Epidemic WHO Technical Report Series no. 894. Geneva: WHO.

2. Bravata DM, Sanders L, Huang J et al. (2003) Efficacy and safety of low-carbohydrate diets. JAMA 289, 1837-1850.

3. Stern L, Iqbal N, Seshadri P et al. (2004) The effects of lowcarbohydrate versus conventional weight loss diets in severely obese adults: one-year follow-up of a randomized trial. Ann Intern Med 140, 778-785.

4. Foster GD, Wyatt HR, Hill JO et al. (2003) A randomized trial of a low-carbohydrate diet for obesity. $N$ Engl J Med 348, 2082-2090.

5. Yancy WS, Olsen MK, Guyton JR et al. (2004) A lowcarbohydrate, ketogenic diet versus a low-fat diet to treat obesity and hyperlipidemia. Ann Intern Med 140, 769-777.

6. Brehm BJ, Seeley RJ, Daniels SR et al. (2003) A randomized trial comparing a very low carbohydrate diet and a calorierestricted low fat diet on body weight and cardiovascular risk factors in healthy women. J Clin Endocrinol Metab 88, $1617-1623$.

7. Atkins RC (1992) Dr. Atkins' New Diet Revolution. New York: Harper Collins.

8. Nordmann AJ, Nordmann A, Briel M et al. (2006) Effects of low-carbohydrate vs low-fat diets on weight loss and cardiovascular risk factors: a meta-analysis of randomized controlled trials. Arch Intern Med 166, 285-293.

9. Dansinger ML, Gleason JA, Griffith JL et al. (2005) Comparison of the Atkins, Ornish, Weight Watchers, and Zone diets for weight loss and heart disease risk reduction: a randomized trial. JAMA 293, 43-53.
10. Sacks FM, Bray GA, Carey VJ et al. (2009) Comparison of weight-loss diets with different compositions of fat, protein, and carbohydrates. N Engl J Med 360, 859-873.

11. Cornier MA, Donahoo WT, Pereira R et al. (2005) Insulin sensitivity determines the effectiveness of dietary macronutrient composition on weight loss in obese women. Obes Res 13, 703-709.

12. Ascaso JF, Romero P, Real JT et al. (2001) Insulin resistance quantification by fasting insulin plasma values and HOMA index in a non-diabetic population. Med Clin (Barc) 117, 530-553.

13. McLaughlin T, Abbasi F, Carantoni M et al. (1999) Differences in insulin resistance do not predict weight loss in response to hypocaloric diets in healthy obese women. J Clin Endocrinol Metab 84, 578-581.

14. De Luis DA, Aller R, Izaola O et al. (2006) Differences in glycaemic status do not predict weight loss in response to hypocaloric diets in obese patients. Clin Nutr 25, $117-122$

15. Kleiner RE, Hutchins AM, Johnston CS et al. (2006) Effects of an 8-week high-protein or high-carbohydrate diet in adults with hyperinsulinemia. MedGenMed $\mathbf{8}$, issue 4, 39.

16. Luscombe ND, Clifton PM, Noakes M et al. (2003) Effect of a high-protein, energy-restricted diet on weight loss and energy expenditure after weight stabilization in hyperinsulinemic subjects. Int J Obes Relat Metab Disord 27, 582-590.

17. Noakes M, Keogh JB, Foster PR et al. (2005) Effect of an energy-restricted, high-protein, low-fat diet relative to a conventional high-carbohydrate, low-fat diet on weight loss, body composition, nutritional status, and markers of cardiovascular health in obese women. Am J Clin Nutr 81, 1298-1306.

18. McLaughlin T, Abbasi F, Cheal K et al. (2003) Use of metabolic markers to identify overweight individuals who are insulin resistant. Ann Intern Med 139, 802-809.

19. McLaughlin T, Carter S, Lamendola C et al. (2006) Effects of moderate variations in macronutrient composition on weight loss and reduction in cardiovascular disease risk in obese, insulin-resistant adults. Am J Clin Nutr 84, 813-821.

20. Laymen DK, Boileau RA, Erickson DJ et al. (2003) A reduced ratio of dietary carbohydrate to protein improves body-composition and blood lipid profiles during weight loss in adult women. $J$ Nutr 133, 411-417.

21. Westerterp-Plantenga MS (2003) The significance of protein in food intake and body weight regulation. Curr Opin Clin Nutr Metab Care 6, 635-638.

22. Skov AR, Toubro S, Ronn B et al. (1999) Randomized trial on protein vs carbohydrate in ad libitum fat reduced diet for the treatment of obesity. Int J Obes Relat Metab Disord 23, 528-536.

23. Dumesnil JG, Turgeon J, Tremblay A et al. (2001) Effect of a low-glycaemic index-low-fat-high-protein diet on the atherogenic metabolic risk profile of abdominally obese men. Br J Nutr 86, 557-568.

24. Pietrobelli A, Allison DB, Heshka S et al. (2002) Sexual dimorphism in the energy content of weight change. Int $J$ Obes Relat Metab Disord 26, 1339-1348.

25. Ferrannini E \& Mari A (1998) How to measure insulin sensitivity. J Hypertens 16, 895-906.

26. McLaughlin TL \& Reaven GM (2003) Beyond type 2 diabetes: the need for a clinically useful way to identify insulin resistance. Am J Med 114, 501-502.

27. Pacini G \& Mari A (2003) Methods for clinical assessment of insulin sensitivity and $\beta$-cell function. Best Pract Res Clin Endocrinol Metab 17, 305-322.

28. Ebbeling CB, Leidig MM, Feldman HA et al. (2007) Effects of a low-glycemic load vs low-fat diet in obese young adults. A randomized trial. JAMA 297, 2092-2102. 